\title{
Heterozygous POLG variant Ser1181Asn co-segregating in a family with autosomal dominant axonal neuropathy, proximal muscle fatigability, ptosis, and ragged red fibers
}

\author{
Maike F. Dohrn ${ }^{1,2^{*}}\left(\mathbb{D}\right.$, Corina Heller ${ }^{3,4}$, Diana Zengeler ${ }^{3,4}$, Carolin D. Obermaier ${ }^{3,4}$ (D), Saskia Biskup ${ }^{3,4}$, \\ Joachim Weis ${ }^{5}$, Stefan Nikolin ${ }^{5}$, Kristl G. Claeys ${ }^{6,7}$, Ulrike Schöne ${ }^{1}$, Danique Beijer ${ }^{2} \mathbb{D}$, Natalie Winter ${ }^{8}$, \\ Pascal Achenbach ${ }^{1,5}$, Burkhard Gess ${ }^{1}$, Jörg B. Schulz ${ }^{1,9}$ and Lejla Mulahasanovic ${ }^{3,4}$
}

\begin{abstract}
By whole-exome sequencing, we found the heterozygous POLG variant c.3542G $>$ A; p.Ser1181 Asn in a family of four affected individuals, presenting with a mixed neuro-myopathic phenotype. The variant is located within the active site of polymerase gamma, in a cluster region associated with an autosomal dominant inheritance. In adolescence, the index developed distal atrophies and weakness, sensory loss, afferent ataxia, double vision, and bilateral ptosis. One older sister presented with Charcot-Marie-Tooth-like symptoms, while the youngest sister and father reported exercise-induced muscle pain and proximal weakness. In none of the individuals, we observed any involvement of the central nervous system. Muscle biopsies obtained from the father and the older sister showed ragged-red fibers, and electron microscopy confirmed mitochondrial damage. We conclude that this novel POLG variant explains this family's phenotype.
\end{abstract}

Keywords: Polymerase gamma, Autosomal dominant, Axonal neuropathy, Myo-neuropathy, Mitochondrial myopathy

\section{Case report}

In her teenage years, the currently 57 -year-old female index patient noticed progressive gait instability, distal muscle weakness, and distal sensory deficits. Fine motor skills worsened, and her vision became remotely doubled with fatigability. Clinically, she showed an advanced distal tetraparesis including steppage gait, sensory deficits on lower legs, afferent ataxia, distal areflexia, and a slight bilateral non-dynamic ptosis. Nerve conduction studies (NCS) confirmed a severe chronic axonal sensorimotor

*Correspondence: mdohrn@ukaachen.de

${ }^{1}$ Department of Neurology, Medical Faculty, RWTH Aachen University, Aachen, Germany

Full list of author information is available at the end of the article polyneuropathy. A detailed patient history and repeated laboratory tests did not reveal any acquired cause of neuropathy.

The index patient (II.3) had two older and one younger sister, of whom the second (II.2) and fourth (II.4) born had neuromuscular symptoms as well, while the oldest sister (II.1) was unaffected (Fig. 1a). Patient II.2 presented with moderate weakness and atrophies in lower legs, distal sensory deficits, hyporeflexia, and pedes cavi. Patient II.4 reported proximal muscle weakness, exercise-induced muscle pain, and cramping. She had previously undergone surgery for bilateral ptosis. Their father (I.1) suffered from proximal muscle weakness and atrophies. His serum creatine kinase was moderately elevated (around $600 \mathrm{U} / \mathrm{l}$; normal $<190 \mathrm{U} / \mathrm{l}$ ), which was not the

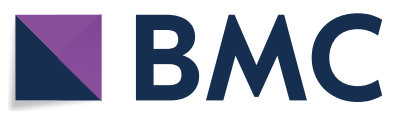

(c) The Author(s) 2022. Open Access This article is licensed under a Creative Commons Attribution 4.0 International License, which permits use, sharing, adaptation, distribution and reproduction in any medium or format, as long as you give appropriate credit to the original author(s) and the source, provide a link to the Creative Commons licence, and indicate if changes were made. The images or other third party material in this article are included in the article's Creative Commons licence, unless indicated otherwise in a credit line to the material. If material is not included in the article's Creative Commons licence and your intended use is not permitted by statutory regulation or exceeds the permitted use, you will need to obtain permission directly from the copyright holder. To view a copy of this licence, visit http://creativecommons.org/licenses/by/4.0/. 


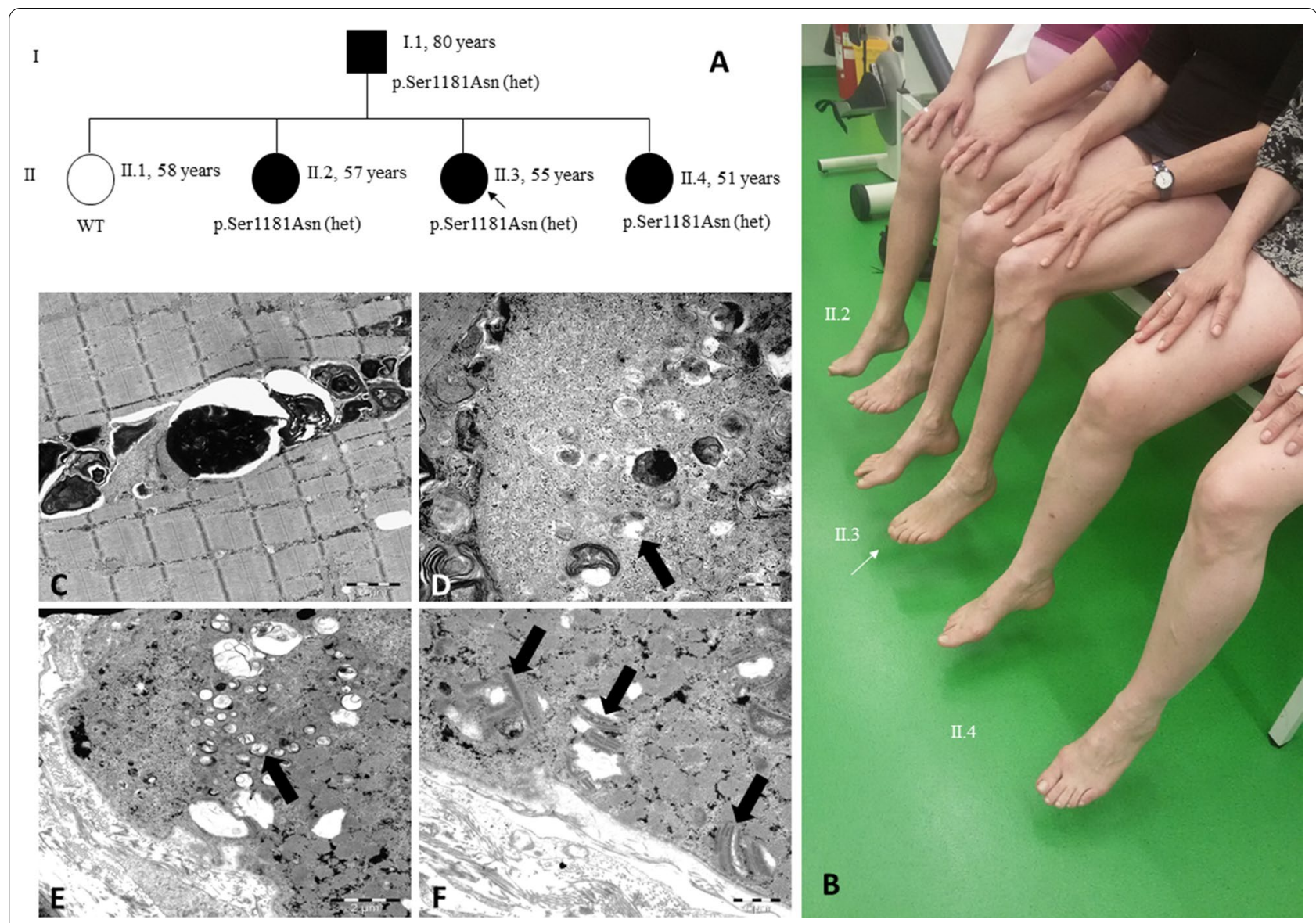

Fig. 1 Pedigree, clinical picture, and electron microscopy. In a family with an affected father, three affected and one unaffected sisters, the novel POLG variant c.3542G >A; p.Ser1181 Asn co-segregates with the phenotype in two generations (a). Clinical features are distal atrophies and high-arched feet in the first (II.2) and second (II.3) oldest affected sister sitting on the right side and in the middle of the bench (b). The youngest sister (II.4) has a pronounced myopathic phenotype. An electron microscopy of the lateral vastus muscle obtained from patient II.2 revealed prominent intermyofibrillar autophagic vacuoles filled with pleomorphic granular and membranous material (c), degenerating mitochondria undergoing (abnormal) mitophagy (arrows; $\mathbf{d}, \mathbf{e}$ ), and paracrystalline inclusions in many mitochondria (arrows, $\mathbf{f}$ ), demonstrating mitochondrial damage

case in any of his daughters. NCS revealed an axonal sensorimotor polyneuropathy in patient I.1 and II.2, but not in patient II.4. We did not observe any significant decrement in the $3 \mathrm{~Hz}$ repetitive muscle stimulation. An electromyogram performed in patient I.1 at the left tibial anterior muscle showed a mixed neuropathic and myopathic pattern.

Whole-exome sequencing performed in patients II.2 and II.3 revealed the heterozygous variant c.3542G $>$ A; p.Ser1181Asn in POLG (NM_001126131.3). Sanger sequencing-based segregation analyses confirmed that all affected family members carried the variant, whereas the unaffected sister (II.1) did not (Fig. 1a, b). A muscle biopsy obtained from patient II.2's right lateral vastus muscle showed signs of denervation as well as a combination of COX-negative and ragged red fibers, which had previously been reported in the father's muscle as well (analysis performed elsewhere). Additionally, the electron microscopy revealed degenerating mitochondria with para-crystalline inclusions as well as mitochondria undergoing impaired mitophagy (Fig. 1c-f).

\section{Discussion}

Polymerase gamma (POLG) is a $140 \mathrm{kDa}$ enzyme responsible for mitochondrial DNA replication [3]. The spectrum of POLG-associated phenotypes is broad, and there is currently no disease-modifying treatment available. With an autosomal recessive mode of inheritance, mtDNA depletion syndromes such as Alpers-Huttenlocher syndrome cause severe encephalopathies with epilepsy, ataxia, parkinsonism, and mental retardation with an onset at early childhood [10]. Autosomal dominant 
disease forms are caused by variants clustering within the DNA-binding palm- and finger-domains [1] and typically manifest with a variable form of external ophthalmoplegia [4], frequently accompanied by generalized myopathy, tremor, or parkinsonism [5]. Axonal neuropathies are part of the known POLG spectrum [7, 12], typically with a sensory-ataxic phenotype [6]. It is further known that the age of onset and the severity of symptoms can vary even within carriers of dominant POLG mutations [2], like in the herein reported family.

Co-segregating in a pedigree of autosomal dominant inheritance, we herein report the heterozygous $P O L G$ variant c.3542G $>$ A; p.Ser1181Asn, for the first time in association with any disease. The variant is located within a hot spot region encoding the polymerase active site: "Holding" the template DNA strand, the so-called palm domain together with the finger and thumb domains are crucial for mitochondrial DNA replication $[3,8,11]$. Functional studies on the variant p.Tyr955Cys, likewise associated with a dominant mode of inheritance [5], showed a significantly reduced nucleotide incorporation rate with a higher amount of replication errors [9]. In-silico predictions for the novel variant c. $3542 \mathrm{G}>\mathrm{A}$; p.Ser1181Asn consistently support its pathogenicity. In the gnomAD population database, the overall allele frequency is 0.00003182 , with a total of nine heterozygotes, which might be explained by a reduced penetrance, a phenomenon that has been previously described for other pathogenic POLG variants.

We conclude that the herein described heterozygous variant c.3542G>A; p.Ser1181Asn in POLG is likely to explain the patients' phenotype. In families with a variable neuro-myopathic syndrome and autosomal dominant inheritance, we would consider $P O L G$ as a fitting molecular genetic cause.

\section{Abbreviations}

CK: Creatine kinase; NCS: Nerve conduction studies; POLG: Polymerase G.

\section{Acknowledgements}

We thank the patient family for their participation and commitment.

\section{Authors' contributions}

MFD: acquisition of data, analysis and interpretation of data, drafting of the manuscript. CH: analysis and interpretation of data. DZ: analysis and interpretation of data. CDO: analysis and interpretation of data. SB: analysis and interpretation of data. JW: analysis and interpretation of data. KGC: acquisition of data. US: acquisition of data. NW: acquisition of data. DB: analysis and interpretation of data. PA: acquisition of data. BG: analysis and interpretation of data. JBS study supervision, critical review of the manuscript; LM: analysis and interpretation of data, study supervision, critical review of the manuscript. All authors read and approved the final manuscript.

\section{Funding}

We did not receive any funding for this case study.

\section{Availability of data and materials}

Not applicable.

\section{Declarations}

\section{Consent for publication}

We obtained the patients' written consent for molecular genetic analyses and further scientific use, as well as for publication.

\section{Competing interests}

Maike F. Dohrn has received scientific funding from Pfizer (ASPIRE 2018), has served as a paid consultant for Amicus, Akcea, Alnylam, and Pfizer, and is currently receiving a scholarship for a research fellowship by the German Research Foundation (Deutsche Forschungsgemeinschaft, DFG). Jörg B. Schulz serves at advisory boards for Biogen and Roche. Burkhard Gess received financial support from Pfizer, Grifols, and Bayer for conference contributions. Natalie Winter has received scientific funding from Pfizer (ASPIRE 2018), has served as a paid consultant for Canon and Pfizer, and is currently receiving an intramural scholarship for a research fellowship (Clinician Scientist). CH, DZ, CDO, SB, JW, KGC, US, PA, and LM have no conflicts to disclose.

\section{Author details}

'Department of Neurology, Medical Faculty, RWTH Aachen University, Aachen, Germany. ${ }^{2}$ Dr. John T. Macdonald Foundation, Department of Human Genetics and John P. Hussman Institute for Human Genomics, University of Miami, Miller School of Medicine, Miami, FL, USA. ${ }^{3}$ Praxis Für Humangenetik Tübingen, Tuebingen, Germany. ${ }^{4} \mathrm{CeGaT} \mathrm{GmbH}$, Tuebingen, Germany. ${ }^{5}$ Institute of Neuropathology, Medical Faculty, RWTH Aachen University, Aachen, Germany. ${ }^{6}$ Department of Neurology, University Hospitals Leuven, Leuven, Belgium. ${ }^{7}$ Laboratory for Muscle Diseases and Neuropathies, KU Leuven, Leuven, Belgium. ${ }^{8}$ Department of Neurology and Epileptology, Hertie Institute for Clinical Brain Research, University of Tuebingen, Tuebingen, Germany. ${ }^{9}$ JARA-BRAIN Institute Molecular Neuroscience and Neuroimaging, Forschungszentrum Jülich GmbH and RWTH Aachen University, Aachen, Germany.

Received: 10 November 2021 Accepted: 30 December 2021 Published online: 01 February 2022

\section{References}

1. Chan, S. S., \& Copeland, W. C. (2009). DNA polymerase gamma and mitochondrial disease: Understanding the consequence of POLG mutations. Biochimica et Biophysica Acta, 1787(5), 312-319.

2. Filosto, M., Mancuso, M., Nishigaki, Y., Pancrudo, J., Harati, Y., Gooch, C., Mankodi, A., Bayne, L., Bonilla, E., \& Shanske, S. (2003). Clinical and genetic heterogeneity in progressive external ophthalmoplegia due to mutations in polymerase $\gamma$. Archives of Neurology, 60(9), 1279-1284.

3. Graziewicz, M. A., Longley, M. J., \& Copeland, W. C. (2006). DNA polymerase $\gamma$ in mitochondrial DNA replication and repair. Chemical Reviews, 106(2), 383-405.

4. Kiechl, S., Horvath, R., Luoma, P., Kiechl-Kohlendorfer, U., Wallacher-Scholz, B., Stucka, R., Thaler, C., Wanschitz, J., Suomalainen, A., \& Jaksch, M. (2004). Two families with autosomal dominant progressive external ophthalmoplegia. Journal of Neurology, Neurosurgery and Psychiatry, 75(8), 1125-1128.

5. Lamantea, E., Tiranti, V., Bordoni, A., Toscano, A., Bono, F., Servidei, S., Papadimitriou, A., Spelbrink, H., Silvestri, L., \& Casari, G. (2002). Mutations of mitochondrial DNA polymerase $\gamma A$ are a frequent cause of autosomal dominant or recessive progressive external ophthalmoplegia. Annals of Neurology, 52(2), 211-219.

6. Lehmann, H. C., Wunderlich, G., Fink, G. R., \& Sommer, C. (2020). Diagnosis of peripheral neuropathy. Neurological Research and Practice, 2(1), 1-7.

7. Mancuso, M., Orsucci, D., Angelini, C., Bertini, E., Carelli, V., Comi, G. P., Federico, A., Minetti, C., Moggio, M., \& Mongini, T. (2016). "Mitochondrial neuropathies": A survey from the large cohort of the Italian Network. Neuromuscular Disorders, 26(4-5), 272-276.

8. Nurminen, A., Farnum, G. A., \& Kaguni, L. S. (2017). Pathogenicity in POLG syndromes: DNA polymerase gamma pathogenicity prediction server and database. BBA Clin, 7, 147-156.

9. Ponamarev, M. V., Longley, M. J., Nguyen, D., Kunkel, T. A., \& Copeland, W. C. (2002). Active site mutation in DNA polymerase $\gamma$ associated with progressive external ophthalmoplegia causes error-prone DNA synthesis. Journal of Biological Chemistry, 277(18), 15225-15228. 
10. Rahman, S., \& Copeland, W. (2019). POLG-related disorders and their neurological manifestations. Nature Reviews. Neurology, 15(1), 40-52.

11. Steitz, T. A. (1999). DNA polymerases: Structural diversity and common mechanisms. Journal of Biological Chemistry, 274(25), 17395-17398.

12. Tchikviladzé, M., Gilleron, M., Maisonobe, T., Galanaud, D., Laforêt, P., Durr, A., Eymard, B., Mochel, F., Ogier, H., \& Béhin, A. (2015). A diagnostic flow chart for POLG-related diseases based on signs sensitivity and specificity. Journal of Neurology, Neurosurgery and Psychiatry, 86(6), 646-654.

\section{Publisher's Note}

Springer Nature remains neutral with regard to jurisdictional claims in published maps and institutional affiliations.

- fast, convenient online submission

- thorough peer review by experienced researchers in your field

- rapid publication on acceptance

- support for research data, including large and complex data types

- gold Open Access which fosters wider collaboration and increased citations

- maximum visibility for your research: over $100 \mathrm{M}$ website views per year

At BMC, research is always in progress.

Learn more biomedcentral.com/submissions 